\title{
Sleep Duration and Sleep Problems in a Representative Sample of German Children and Adolescents*
}

\author{
Angelika A. Schlarb 1,2, Marco D. Gulewitsch², Victoria Weltzer², \\ Ute Ellert ${ }^{3}$, Paul Enck ${ }^{4}$ \\ ${ }^{1}$ Department of Psychology and Sports, University of Bielefeld, Bielefeld, Germany \\ ${ }^{2}$ Faculty of Science, Department of Psychology, University of Tuebingen, Tuebingen, Germany \\ ${ }^{3}$ Department of Epidemiology, Health Monitoring, Robert Koch-Institute, Berlin, Germany \\ ${ }^{4}$ Department of Internal Medicine VI: Psychosomatic Medicine and Psychotherapy, University Hospital \\ Tuebingen, Germany \\ Email: angelika.schlarb@uni-bielefeld.de
}

Received 23 September 2015; accepted 1 November 2015; published 4 November 2015

Copyright (C) 2015 by authors and Scientific Research Publishing Inc.

This work is licensed under the Creative Commons Attribution International License (CC BY).

http://creativecommons.org/licenses/by/4.0/

(c) (i) Open Access

\section{Abstract}

Objective: The main purpose of the present study was to evaluate sleep duration for nighttime sleep from early infancy to late adolescence in a German sample to illustrate the developmental course and age-specific variability of these variables among subjects. Methods: A total of 17,641 subjects from the KiGGS study were evaluated. The questionnaires contained questions about physical health, living circumstances, health behavior and risks, health supply, mental health, health-related quality of life and sleep. KiGGS assessed sleep by using parent questionnaire of children aged 0 to 10 years $(n=9944)$ and self-reports of adolescents $(n=7697)$ aged 11 to 17 years. Results: Total sleep duration decreased from 14.28 hours $(S D=2.33)$ at the ages 0 - 0.5 to 9.50 hours $(S D=0.82)$ at the ages of $10.5-11$. Above the age of 11 adolescents report a decrease of sleep at night from 9.41 hours $(S D=1.33)$ at the age of $11-11.5$ to $7.42(S D=1.73)$ at the age of 17.5 - 18 years. Unspecified sleep problems were reported of $19.5 \%, 13.0 \%$ of the children had difficulties falling asleep, difficulties sleeping through the night showed $8.8 \%$ of the children, whereas 3.0\% report both symptoms-difficulties falling asleep and difficulties sleeping through the night. Conclusions: Age-specific variability of sleep duration is reported as well as sleep difficulties from infancy to adolescence. This is important knowledge for the health care professional who deals with sleep problems in pediatric practice.

\footnotetext{
*The items concerning sleep problems used in KiGGS do not provide diagnostics of sleep disorders—for this reason, the terms "sleep difficulties" or "sleep problems" will be used synonymously.

How to cite this paper: Schlarb, A.A., Gulewitsch, M.D., Weltzer, V., Ellert, U. and Enck, P. (2015) Sleep Duration and Sleep Problems in a Representative Sample of German Children and Adolescents. Health, 7, 1397-1408. 


\section{Keywords}

\section{Sleep Duration, Infants, Children, Adolescents, Sleep Problems}

\section{Introduction}

Sleep duration changes remarkably during the first years of life. Several studies reported individual as well as interindividual decrease of amount of sleep during early infancy and childhood to adolescence [1]-[9]. Sleep duration of children and adolescents aged 1 month to 16 years in Switzerland $(n=493)$ decreases from averagely 14.2 hours at 6 months to averagely 8.1 hours at 16 years [9]. Normally, during the first years night sleep duration increases slightly whereas day sleep decreases [5]. During the first year of life, the number of episodes of sleep is reduced by about $50 \%$, but total sleep time is reduced by only two hours [4]. In sum, various studies demonstrated that in childhood and adolescence, nocturnal sleep time decreases, bedtimes are delayed and differences between weekend and school day sleep increase with age [1] [2] [10]-[12].

In general, over the last decades a tendency towards reduced sleep duration in children and adolescents can be observed worldwide. For example, Dollman et al. investigated trends in the duration of school-day sleep among 10- to 15-year-old Australians between 1985 and $2004(\mathrm{n}=900)$ and found that in 1985 the total sleep time was 9.24 hours-in 2004, it was 8.74 hours [13]. In detail, sleep duration declined (28 minutes for girls and 33 minutes for boys) because of later bed times, whereas the school start times remained stable [13]. Also Iglowstein and colleagues also demonstrated that total sleep duration decreased in the recent 30 years because of later bed times: For example, in the mid-1970s mean bedtime in children aged 2 years was at 7:08 p.m., in the 1990s mean bedtime was 7:46 p.m. [9].

The main causes of less sleep in older children are later bed times due to socio-cultural factors, high levels of nighttime and recreational activities, as well as excessive academic activities [6]. In addition, also pubertal phase delay which significantly affects the sleep-wake schedule, quality of sleep, as well as daytime behavior can significantly reduce hours available to sleep.

Furthermore, culture-specific differences regarding sleep duration are observable: A comparative study accomplished by researchers in the USA and China within children aged 7 to 13 years, showed that Chinese children sleep averagely 9.13 hours whereas US children sleep 10.64 hours [7]. Tynjälä and colleges outlined in a study with 40,202 Europeans from 11 countries aged 11 to 16 years significant differences in sleep duration between countries-for example Swiss children report the longest sleep duration whereas Israeli and Finnish children have the shortest duration of sleep [14]. Furthermore, a cross-sectional and longitudinal study with 668 subjects aged 1 to 20 years confirmed, that Icelandic adolescents aged 11, 13 and 15 have delayed bedtimes and shorter nocturnal sleep compared to European peers [10].

Several studies suggested that many children and adolescents do not obtain adequate nocturnal sleep [15]-[19]. In a Chinese cross-sectional survey with children aged 5 to 11 years $(n=20,778), 28.3 \%$ sleep less than 9 hours per night [20]. An Australian study shows that $23.9 \%$ of 3495 children and adolescents aged 5 to 15 years sleep less than 9 hours [21]. Also Padez and colleges demonstrated that $45.9 \%$ of Portuguese children aged 7 to 9 years $(n=4511)$ sleep less than 9 hours [22]. 25\% of American adolescents report sleeping 6 hours or less per night [23]. Loessl and colleges confirmed this phenomenon and emphasized that $91.6 \%$ of 601 German students aged 12 to 18 years sleep less than 9.2 hours per night during the week [24]. But too long sleep duration is also a risk factor for physical impairments (e.g. fitness) [25]. The percentage of children and adolescents with long and short sleep duration differs, not only in age groups and countries but also over the years [9].

Besides changes in sleep duration over the last decades, sleep research illustrated a considerable percentage of sleep disorders in children and adolescents: About $25 \%$ of all children experience some type of sleep problemsmostly difficulties falling asleep or sleeping through the night—at some point during childhood [26], but it has to be taken into account that prevalence rates of insomnia changes due to diagnostic criteria in age groups and countries [27]. In an epidemiological survey $(n=5979)$ among children in the age of 2 to 12 years old living in China, the overall prevalence of sleep disorders was 21.2\% [8]. In Spain, García-Jiménez et al. determined in a study with adolescents that $23.1 \%$ had difficulties in getting to sleep, $38.2 \%$ wake up during the night and $15.9 \%$ wake up too early-and $38.55 \%$ of adolescents reported poor sleep quality [12]. In a previous study with 
German children, 5\% of 1400 children at school enrollment, aged averagely 5.52 years old, experience sleep problems like falling asleep or sleeping through the night frequently [28]. Boys and girls differ in the prevalence of sleep disorders: Gender differences in sleep may become apparent after the onset of puberty because of hormonal changes [29]. Gender-related differences in sleep disorders include differences in prevalence [29]: The onset of menses was associated with a 2.75-fold increased risk for insomnia [30]. As Iglowstein et al. [9] emphasized, knowledge of sleep characteristics - such as sleep duration and percentage of short and long sleepers-is important to complete the comprehension of sleep disorders because disproportionate sleep duration is an evident association for sleep problems as difficulties falling asleep, night wakings and early morning wakings. To avoid these sleep disturbances, nighttime and daytime sleep should be adjusted to the age of children and adolescents [9].

The Robert Koch Institute (RKI, Berlin, Germany) initiated in 2006 a nationally representative cross-sectional survey (KiGGS) studying health and circumstances of life in children and adolescents aged between 0 and 17 years living in Germany $(n=17,641)$ [31]. The epidemiology of difficulties falling asleep and/or sleeping through the night, the total sleep duration and percentage of long and short sleepers can be ascertained for a large sample of children and adolescents. Furthermore, comparisons with results of the last decades of different countries respective sleep duration are possible.

\section{Methods}

\subsection{Procedure and Participants}

KiGGS is a nationally representative cross-sectional community-based survey studying health and circumstances of life in children and adolescents aged between 0 and 17 years living in Germany [32]. It was performed by the Robert Koch Institute (RKI, Berlin) between May 2003 and May 2006. The RKI conducted a 2-stage-sampling procedure: Sampling involved a random selection of 167 communities stratified by federal state, community type and size, followed by random selection of an equal number of children per birth year from local population registries (Centre for Survey Research and Methodology, Mannheim, Germany). The participation rate was 66.6\% [33]. For further information on the KiGGS methodology, see the detailed survey literature [31]-[34]. Altogether 17,641 children (9052 (51.3\%) boys and 8589 (48.7\%) girls) took part in KiGGS. Mean age of children and adolescents was 9.61 years.

\subsection{Material}

The questionnaire contained questions about physical health, living circumstances, health behaviour and risks, health supply, mental health, health-related quality of life and sleep. KiGGS assessed sleep by using parent questionnaire of children aged 0 to 10 years $(n=9944: 5101(51.3 \%)$ boys, $4843(48.7 \%)$ girls) and self-reports of adolescents ( $\mathrm{n}=7697: 3951$ (51.3\%) boys, 3747 (48.7\%) girls) aged 11 to 17 years.

\section{Questions about Sleep}

To assess sleep problems in childhood, KiGGS acted in accordance with the criteria for insomnia [35]. Parents were asked how many hours the child sleeps per day and night averagely ("How many hours does your child sleep averagely?"). Furthermore they were asked if the child does suffer from sleep difficulties ("Does your child suffer from sleep difficulties?”). If yes, parents should answer whether the child has difficulties to fall asleep or if the child has difficulties to sleep through the night ("My child has difficulties to fall asleep.”/“My child has difficulties to sleep through the night.”). Questions concerning difficulties falling asleep or sleep through the night were rated as "no" if the initial question on sleep problems in general was negated. Except for the first question on sleep duration, possible answers were "yes" or "no". Inclusion criteria for subsequent analyses, was no missing data in the initial question about sleep problems in general (17,102 of 17,641 participants $=96.9 \%$ ).

\subsection{Statistical Analysis}

The statistical analysis contained three steps: First, the sleep duration of children and adolescents ( 0 - 17 years in half-year steps) was determined. In a second step, we analyzed the prevalence of sleep problems ("sleep problems in general", "difficulties falling asleep" and "difficulties sleeping through the night") for the complete 
sample as well as for age groups ( 0 - 2 years, 3 - 6 years, 7 - 10 years, 11 - 13 years and 14 - 17 years). In the last step, we determined the association between short or long sleepers and sleep problems. All analyses are available for boys, girls and both and include gender difference analyses. To get nationwide representative results with respect to age, sex, place of residency, and nationality a validated weighting factor was used for all analyses. The number of cases $(\mathrm{N})$ may vary due to this weighting factor. Statistical analyses were accomplished by chi-square tests and univariate logistic regression models to estimate odds ratios (OR). Because of the high statistical power resulting from the large sample size, the level of significance was set at $\mathrm{p} \leq 0.01$. All data were analysed using PASW ${ }^{\circledR}$ Statistics 18.

\section{Results}

\subsection{Sleep Duration}

According to parents' reports, the total amount of sleep per day decreases steadily from 14.28 hours (sd = 2.33) at the ages $0-0.5$ to 9.50 hours $(\mathrm{sd}=0.82)$ at the ages of $10.5-11$. The interindividual differences (standard deviations) decrease in a similar way. Across all ages there are no remarkable differences between boys and girls. Above the age of 11 this information was interviewed via self report from the adolescents: They report a decrease of sleep at night from 9.41 hours $(s d=1.33)$ at the age of $11-11.5$ to $7.43(s d=1.73)$ at the age of 17.5 - 18 years. Similar to parents' reports, adolescents' self reports show also a decrease in interindividual differences (sd) and do not reveal distinct gender differences. A comprehensive view about the developmental course of sleep duration during childhood (parents' report) and adolescence (self report) is given in Table 1 resp. Table 2 (percentiles). Figure 1 and Figure 2 display the development of sleep duration and interindividual variance.

\subsection{Prevalence of Sleep Problems}

Across the complete sample including children and adolescents, $19.5 \%$ of participants are reported to have or report having sleep problems in general (details in Table 3). This finding goes along with a significant difference between boys and girls: While $18.0 \%$ of the boys are affected by sleep problems, $21.0 \%$ of the girls are (p $=0.000$ ). Thirteen percent of children and adolescents have difficulties falling asleep, accompanied by a significantly increased prevalence in girls $(14.0 \%)$ compared to boys $(12.0 \%, \mathrm{p}=0.000)$. Difficulties sleeping through the night arise in $8.8 \%$ of children and adolescents, which is again associated with a significant gender difference of $7.8 \%$ of the boys vs. $9.9 \%$ of the girls $(p=0.000)$. The combination of difficulties falling asleep and difficulties sleeping through the night occurs in $3.0 \%$ of cases $(2.4 \%$ of boys vs. $3.6 \%$ of girls, $p=0.000)$.

In toddlers ( 0 - 2 years) difficulties sleeping through the night are quite prevalent (17.5\%), whereas difficulties falling asleep are reported in $8.7 \%$ of cases. Sleep problems in general are reported in $22.6 \%$ of participants between 0 - 2 years. In this age group no significant differences between boys and girls can be identified.

The age group between 3 and 6 years presents a prevalence of $16.0 \%$ of sleep problems in general with no differences between boys and girls. Nine percent of parents report difficulties falling asleep and 9.4\% difficulties sleeping through the night. Combined difficulties of falling asleep and difficulties sleeping through the night affect $2.7 \%$ of children in this age group.

School children between 7 - 10 years are reported to present a similar and also gender-independent rate of sleep problems in general as in children between 3 and 6 years. An increase in difficulties falling asleep (13.6\%) and a decrease in difficulties sleeping through the night (4.9\%) is salient. As in children between 3 and 6 years, difficulties falling asleep and difficulties sleeping are stated in $2.7 \%$.

The self report of adolescents between 11 and 13 years shows the highest prevalence of sleep problems in general among all age groups (23.1\%). Difficulties falling asleep (17.0\%) are also most prevalent in this age group. Difficulties sleeping through the night affect $7.8 \%$ of adolescents between 11 and 13, whereas the combination of difficulties falling asleep and difficulties sleeping through night occurs least often (2.2\%) among all ages.

The results of the oldest age group (14 - 17 years) are characterized by consistent differences between boys and girls. Sleep problems in general are reported by $20.7 \%$ of adolescents while girls are notably more affected $(24.8 \%)$ than boys $(16.7 \%, \mathrm{p}=0.000)$. In this age group girls show an elevated risk of developing sleep problems $(\mathrm{OR}=1.42$, 99\%-CI $=1.24$ - 1.66). Difficulties falling asleep $(15.1 \%)$ are also varying with respect to gender: $15.1 \%$ of boys vs. $17.6 \%$ of girls $(p=0.000)$. A remarkable difference between boys and girls also be- 
comes clear in terms of difficulties sleeping through the night: Whereas only $5.1 \%$ of boys report this disturbance, $11.0 \%$ of the girls state having difficulties sleeping through the night $(\mathrm{p}=0.000)$. Combined difficulties of falling asleep and difficulties sleeping through the night affects adolescent girls more frequently $(4.8 \%)$ than

Table 1. Development of sleep duration in childhood (parents' report) and adolescence (self report).

\begin{tabular}{|c|c|c|c|c|c|c|c|c|c|}
\hline \multirow{2}{*}{ age (years) } & \multicolumn{3}{|c|}{ both genders } & \multicolumn{3}{|c|}{ boys } & \multicolumn{3}{|c|}{ girls } \\
\hline & $\mathrm{n}$ & $\mathrm{m}$ & sd & $\mathrm{n}$ & $\mathrm{m}$ & sd & $\mathrm{n}$ & $\mathrm{m}$ & sd \\
\hline \multicolumn{10}{|c|}{ parents' report: Amount of sleep all day } \\
\hline $0.0-0.5$ & 224 & 14.28 & 2.33 & 115 & 13.98 & 2.36 & 109 & 14.59 & 2.26 \\
\hline$>0.5-1$ & 421 & 13.43 & 1.69 & 212 & 13.34 & 1.86 & 209 & 13.52 & 1.50 \\
\hline$>1.0-1.5$ & 389 & 13.11 & 1.53 & 201 & 13.17 & 1.57 & 189 & 13.05 & 1.49 \\
\hline$>1.5-2.0$ & 426 & 12.77 & 1.45 & 216 & 12.77 & 1.50 & 209 & 12.77 & 1.39 \\
\hline$>2.0-2.5$ & 431 & 12.49 & 1.30 & 219 & 12.44 & 1.28 & 213 & 12.55 & 1.32 \\
\hline$>2.5-3.0$ & 415 & 11.98 & 1.42 & 222 & 11.85 & 1.40 & 193 & 12.14 & 1.45 \\
\hline$>3.0-3.5$ & 403 & 11.57 & 1.19 & 209 & 11.67 & 1.14 & 193 & 11.45 & 1.23 \\
\hline$>3.5-4.0$ & 456 & 11.30 & 1.20 & 230 & 11.28 & 1.20 & 226 & 11.32 & 1.20 \\
\hline$>4.0-4.5$ & 437 & 11.10 & 1.13 & 222 & 11.15 & 1.14 & 215 & 11.04 & 1.12 \\
\hline$>4.5-5.0$ & 461 & 10.90 & 1.02 & 246 & 10.97 & 1.04 & 215 & 10.81 & 0.99 \\
\hline$>5.0-5.5$ & 450 & 10.89 & 1.00 & 227 & 10.95 & 1.02 & 223 & 10.83 & 0.97 \\
\hline$>5.5-6.0$ & 460 & 10.72 & 1.07 & 240 & 10.60 & 0.97 & 220 & 10.85 & 1.15 \\
\hline$>6.0-6.5$ & 465 & 10.53 & 0.98 & 236 & 10.48 & 1.05 & 229 & 10.59 & 0.91 \\
\hline$>6.5-7.0$ & 476 & 10.44 & 0.84 & 246 & 10.45 & 0.83 & 230 & 10.43 & 0.85 \\
\hline$>7.0-7.5$ & 496 & 10.29 & 0.79 & 257 & 10.27 & 0.78 & 239 & 10.32 & 0.79 \\
\hline$>7.5-8.0$ & 459 & 10.15 & 0.91 & 235 & 10.12 & 0.92 & 224 & 10.19 & 0.89 \\
\hline$>8.0-8.5$ & 466 & 10.04 & 0.90 & 220 & 10.05 & 0.92 & 245 & 10.04 & 0.88 \\
\hline$>8.5-9.0$ & 470 & 9.93 & 0.86 & 258 & 9.88 & 0.85 & 212 & 10.00 & 0.86 \\
\hline$>9.0-9.5$ & 491 & 9.88 & 0.86 & 247 & 9.86 & 0.83 & 244 & 9.90 & 0.89 \\
\hline$>9.5-10.0$ & 429 & 9.76 & 0.83 & 226 & 9.84 & 0.84 & 204 & 9.67 & 0.82 \\
\hline$>10-10.5$ & 475 & 9.61 & 0.80 & 240 & 9.59 & 0.79 & 234 & 9.64 & 0.81 \\
\hline$>10.5-11.0$ & 452 & 9.50 & 0.82 & 237 & 9.49 & 0.79 & 215 & 9.52 & 0.85 \\
\hline \multicolumn{10}{|c|}{ self report: Amount of sleep last night } \\
\hline$>11.0-11.5$ & 472 & 9.41 & 1.33 & 251 & 9.41 & 1.40 & 221 & 9.41 & 1.25 \\
\hline$>11.5-12.0$ & 499 & 9.36 & 1.45 & 252 & 9.38 & 1.56 & 247 & 9.34 & 1.33 \\
\hline$>12.0-12.5$ & 507 & 9.14 & 1.58 & 253 & 9.30 & 1.50 & 254 & 8.97 & 1.65 \\
\hline$>12.5-13.0$ & 471 & 9.00 & 1.42 & 247 & 8.97 & 1.21 & 224 & 9.04 & 1.61 \\
\hline$>13.0-13.5$ & 511 & 8.87 & 1.37 & 261 & 8.95 & 1.43 & 250 & 8.79 & 1.31 \\
\hline$>13.5-14.0$ & 531 & 8.77 & 1.33 & 265 & 8.81 & 1.31 & 266 & 8.74 & 1.35 \\
\hline$>14.0-14.5$ & 534 & 8.60 & 1.49 & 287 & 8.70 & 1.45 & 248 & 8.48 & 1.53 \\
\hline$>14.5-15.0$ & 599 & 8.31 & 1.28 & 292 & 8.47 & 1.30 & 307 & 8.15 & 1.24 \\
\hline$>15.0-15.5$ & 584 & 8.18 & 1.31 & 298 & 8.12 & 1.24 & 287 & 8.23 & 1.38 \\
\hline$>15.5-16.0$ & 555 & 7.90 & 1.48 & 290 & 8.05 & 1.43 & 265 & 7.74 & 1.52 \\
\hline$>16.0-16.5$ & 600 & 7.91 & 1.52 & 314 & 7.96 & 1.60 & 286 & 7.86 & 1.42 \\
\hline$>16.5-17.0$ & 561 & 7.66 & 1.47 & 279 & 7.55 & 1.54 & 282 & 7.77 & 1.39 \\
\hline$>17.0-17.5$ & 600 & 7.68 & 1.64 & 312 & 7.74 & 1.69 & 288 & 7.61 & 1.57 \\
\hline$>17.5-18.0$ & 542 & 7.43 & 1.73 & 275 & 7.23 & 1.95 & 267 & 7.63 & 1.44 \\
\hline
\end{tabular}


boys (1.7\%, p = 0.000; overall prevalence: 3.2\%). All details can be obtained from Table 4. Figure 3 serves as a graphical comparison of the prevalence of mentioned sleep problems between the five age groups.

As shown in Table 5, short sleep duration is significantly associated with sleep problems in all age groups. Two univariate logistic regression models covering age groups childhood and adolescence show that sleeping short at night increases the risk for sleep problems in adolescence $(\mathrm{OR}=1.79,99 \%-\mathrm{CI}=1.53-2.10)$, but not in childhood (OR $=0.99,99 \%-C I=0.85-1.15)$. Because of the high prevalence of sleep problems in short sleeping 11 - 13 year olds, this age group shows a specific strong association between short sleeping and sleep problems $(\mathrm{OR}=3.11,99 \%-\mathrm{CI}=2.22-4.35)$.

Table 2. Percentiles of sleep duration (boys and girls).

\begin{tabular}{|c|c|c|c|c|}
\hline age & $\mathrm{M}$ & $\mathrm{P} 2$ & P50 & P98 \\
\hline $0-0.5$ & 14.28 & 10.00 & 14.00 & 18.00 \\
\hline$>0.5-1$ & 13.43 & 10.00 & 14.00 & 16.68 \\
\hline$>1.0-1.5$ & 13.11 & 9.57 & 13.00 & 16.00 \\
\hline$>1.5-2.0$ & 12.77 & 10.00 & 13.00 & 15.00 \\
\hline$>2.0-2.5$ & 12.49 & 10.00 & 13.00 & 15.00 \\
\hline$>2.5-3.0$ & 11.98 & 9.00 & 12.00 & 15.00 \\
\hline$>3.0-3.5$ & 11.57 & 8.73 & 12.00 & 14.00 \\
\hline$>3.5-4.0$ & 11.30 & 8.00 & 11.00 & 14.00 \\
\hline$>4.0-4.5$ & 11.10 & 8.94 & 11.00 & 14.00 \\
\hline$>4.5-5.0$ & 10.90 & 9.00 & 11.00 & 13.00 \\
\hline$>5.0-5.5$ & 10.89 & 8.00 & 11.00 & 13.00 \\
\hline$>5.5-6.0$ & 10.72 & 8.00 & 11.00 & 13.00 \\
\hline$>6.0-6.5$ & 10.53 & 9.00 & 10.16 & 13.00 \\
\hline$>6.5-7.0$ & 10.44 & 9.00 & 10.00 & 12.00 \\
\hline$>7.0-7.5$ & 10.29 & 8.00 & 10.00 & 12.00 \\
\hline$>7.5-8.0$ & 10.15 & 8.00 & 10.00 & 12.00 \\
\hline$>8.0-8.5$ & 10.04 & 8.00 & 10.00 & 12.00 \\
\hline$>8.5-9.0$ & 9.93 & 8.00 & 10.00 & 12.00 \\
\hline$>9.0-9.5$ & 9.88 & 8.00 & 10.00 & 12.00 \\
\hline$>9.5-10.0$ & 9.76 & 8.00 & 10.00 & 11.00 \\
\hline$>10-10.5$ & 9.61 & 8.00 & 10.00 & 11.00 \\
\hline$>10.5-11.0$ & 9.50 & 8.00 & 10.00 & 11.00 \\
\hline$>11-11.5$ & 9.41 & 6.00 & 10.00 & 12.00 \\
\hline$>11.5-12.0$ & 9.36 & 6.00 & 9.00 & 12.00 \\
\hline$>12.0-12.5$ & 9.14 & 5.00 & 9.00 & 12.00 \\
\hline$>12.5-13.0$ & 9.00 & 6.00 & 9.00 & 12.00 \\
\hline$>13-13.5$ & 8.87 & 6.00 & 9.00 & 12.00 \\
\hline$>13.5-14.0$ & 8.77 & 6.00 & 9.00 & 12.00 \\
\hline$>14-14.5$ & 8.60 & 5.14 & 9.00 & 12.00 \\
\hline$>14.5-15.0$ & 8.31 & 6.00 & 8.00 & 11.00 \\
\hline$>15-15.5$ & 8.18 & 5.00 & 8.00 & 11.00 \\
\hline$>15.5-16.0$ & 7.90 & 4.00 & 8.00 & 11.00 \\
\hline$>16-16.5$ & 7.91 & 5.00 & 8.00 & 11.00 \\
\hline$>16.5$ - 17.0 & 7.66 & 4.00 & 8.00 & 11.00 \\
\hline$>17-17.5$ & 7.68 & 4.00 & 8.00 & 12.00 \\
\hline$>17.5$ - 18.0 & 7.43 & 4.00 & 7.00 & 12.00 \\
\hline
\end{tabular}




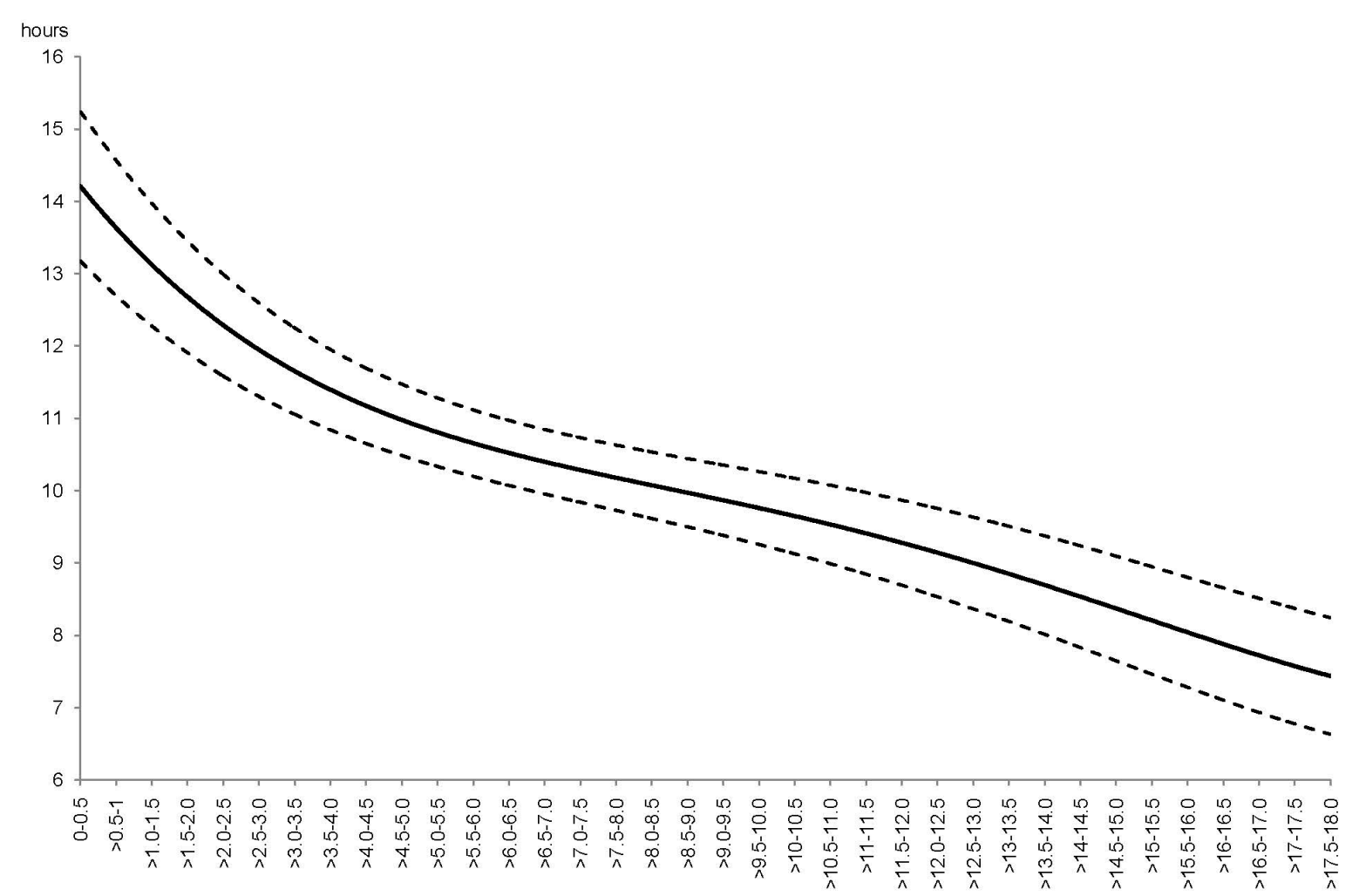

Figure 1. Sleep duration and standard deviation from infancy (parent's report) to adolescence (self report). Smoothed curves are displayed as 4th order polynomial trendlines.

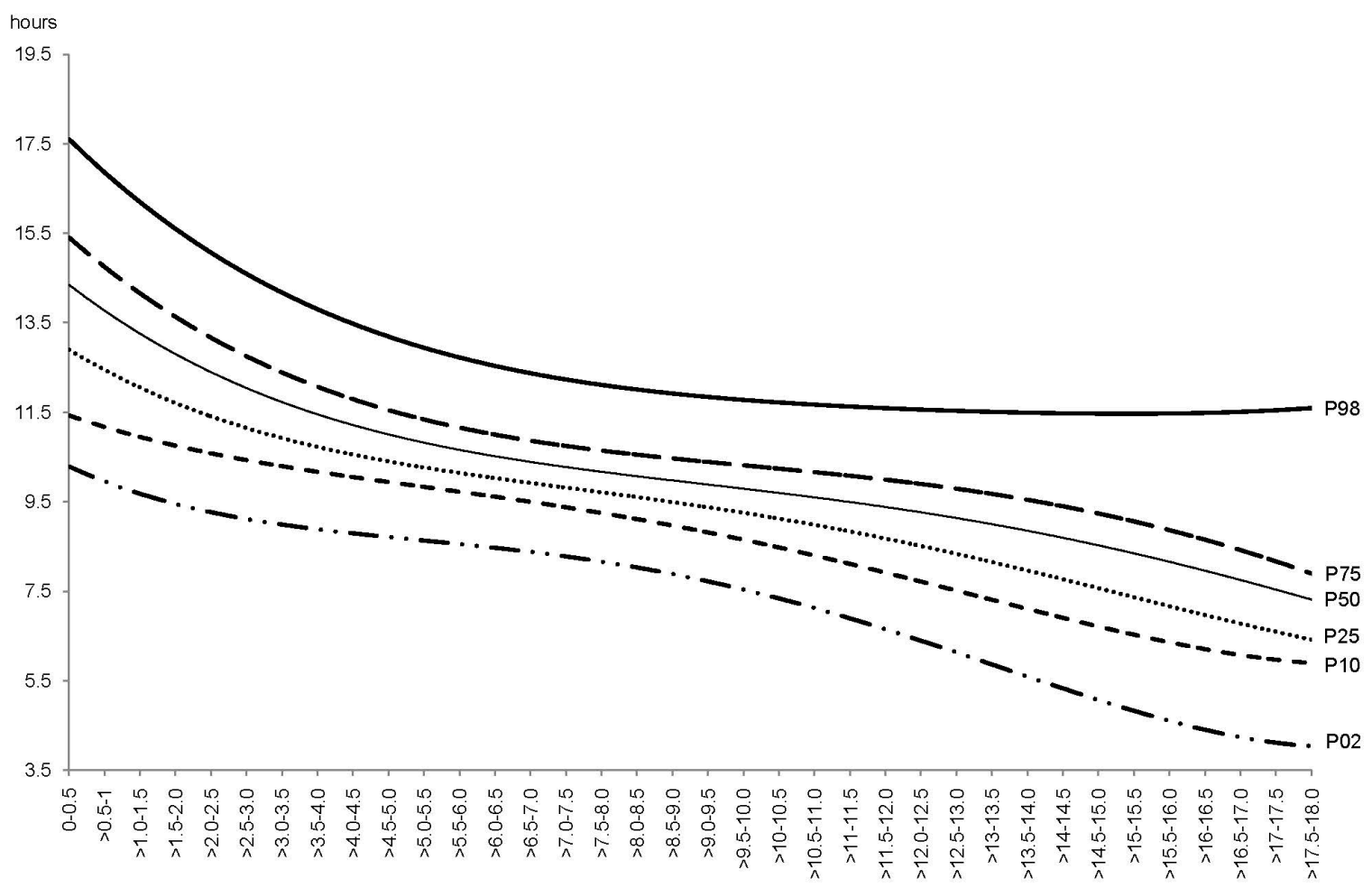

Figure 2. Percentiles of sleep duration from infancy (parent's report) to adolescence (self report). Smoothed curves are displayed as 4th order polynomial trendlines. 
Table 3. Prevalence of sleep problems including the complete sample.

\begin{tabular}{lccccccc}
\hline & \multicolumn{2}{c}{ both genders } & \multicolumn{2}{c}{ boys } & \multicolumn{2}{c}{ girls } & gender difference \\
\cline { 2 - 7 } & $\mathrm{n}$ & $\%$ & $\mathrm{n}$ & $\%$ & $\mathrm{n}$ & $\%$ & \\
\hline unspecified sleep problems & $3327 / 17,102$ & $19.5 \%$ & $1577 / 8778$ & $18.0 \%$ & $1750 / 8324$ & $21.0 \%$ & $\chi^{2}=25.501, \mathrm{p}=0.000$ \\
difficulties falling asleep & $2221 / 17,102$ & $13.0 \%$ & $1052 / 8778$ & $12.0 \%$ & $1169 / 8323$ & $14.0 \%$ & $\chi^{2}=16.057, \mathrm{p}=0.000$ \\
difficulties sleeping through the night & $1509 / 17,102$ & $8.8 \%$ & $688 / 8778$ & $7.8 \%$ & $821 / 8324$ & $9.9 \%$ & $\chi^{2}=21.783, \mathrm{p}=0.000$ \\
difficulties falling asleep and difficulties & $511 / 17,101$ & $3.0 \%$ & $213 / 8778$ & $2.4 \%$ & $298 / 8323$ & $3.6 \%$ & $\chi^{2}=19.624, \mathrm{p}=0.000$ \\
\hline
\end{tabular}

Table 4. Prevalence of sleep problems separated for aged populations and perspective.

\begin{tabular}{|c|c|c|c|c|c|c|}
\hline \multirow{2}{*}{0 - 2 years (parents’ report) } & \multicolumn{2}{|c|}{ both genders } & \multicolumn{2}{|c|}{ boys } & girls & \multirow{2}{*}{ gender difference } \\
\hline & $\mathrm{n}$ & $\%$ & $\mathrm{n}$ & $\%$ & $\mathrm{n}$ & \\
\hline sleep problems in general & $514 / 2275$ & $22.6 \%$ & $259 / 1172$ & $22.1 \%$ & $255 / 1103$ & $23.1 \% \chi^{2}=0.338, \mathrm{p}=0.561$ \\
\hline difficulties falling asleep & $198 / 2275$ & $8.7 \%$ & $95 / 1172$ & $8.1 \%$ & $103 / 1103$ & $9.3 \% \quad \chi^{2}=1.086, \mathrm{p}=0.297$ \\
\hline difficulties sleeping through the night & $398 / 2275$ & $17.5 \%$ & $205 / 1172$ & $17.5 \%$ & $193 / 1103$ & $17.5 \% \chi^{2}=0.000, \mathrm{p}=0.997$ \\
\hline $\begin{array}{l}\text { difficulties falling asleep and difficulties } \\
\text { sleeping through the night }\end{array}$ & $103 / 2275$ & $4.5 \%$ & $51 / 1172$ & $4.4 \%$ & $52 / 1103$ & $4.7 \% \quad \chi^{2}=0.173, p=0.677$ \\
\hline \multicolumn{7}{|l|}{3 - 6 years (parents’ report) } \\
\hline sleep problems in general & $563 / 3528$ & $16.0 \%$ & $272 / 1819$ & $15.0 \%$ & $291 / 1709$ & $17.0 \% \chi^{2}=2.827, \mathrm{p}=0.093$ \\
\hline difficulties falling asleep & $317 / 3529$ & $9.0 \%$ & $157 / 1819$ & $8.6 \%$ & $160 / 1710$ & $9.4 \% \quad \chi^{2}=0.568, p=0.451$ \\
\hline difficulties sleeping through the night & $330 / 3529$ & $9.4 \%$ & $154 / 1819$ & $8.5 \%$ & $176 / 1710$ & $10.3 \% \chi^{2}=3.468, p=0.063$ \\
\hline $\begin{array}{l}\text { difficulties falling asleep and difficulties sleeping } \\
\text { through the night }\end{array}$ & $96 / 3528$ & $2.7 \%$ & $45 / 1819$ & $2.5 \%$ & $51 / 1709$ & $3.0 \% \quad \chi^{2}=0.867, \mathrm{p}=0.352$ \\
\hline \multicolumn{7}{|l|}{7 - 10 years (parents’ report) } \\
\hline sleep problems in general & $607 / 3698$ & $16.4 \%$ & $321 / 1898$ & $16.9 \%$ & $286 / 1800$ & $15.9 \% \chi^{2}=0.706, \mathrm{p}=0.401$ \\
\hline difficulties falling asleep & $502 / 3699$ & $13.6 \%$ & 258/1899 & $13.6 \%$ & $244 / 1800$ & $13.6 \% \chi^{2}=0.001, \mathrm{p}=0.978$ \\
\hline difficulties sleeping through the night & $182 / 3699$ & $4.9 \%$ & $100 / 1899$ & $5.3 \%$ & $82 / 1800$ & $4.6 \% \quad \chi^{2}=0.997, \mathrm{p}=0.318$ \\
\hline $\begin{array}{l}\text { difficulties falling asleep and difficulties sleeping } \\
\text { through the night }\end{array}$ & 101/3699 & $2.7 \%$ & $52 / 1899$ & $2.7 \%$ & 49/1800 & $2.7 \% \quad \chi^{2}=0.001, \mathrm{p}=0.976$ \\
\hline \multicolumn{7}{|l|}{11 - 13 years (self report) } \\
\hline sleep problems in general & $695 / 3009$ & $23.1 \%$ & $332 / 1535$ & $21.6 \%$ & $363 / 1474$ & $24.6 \% \chi^{2}=3.805, \mathrm{p}=0.051$ \\
\hline difficulties falling asleep & $513 / 3009$ & $17.0 \%$ & $243 / 1535$ & $15.8 \%$ & $20 / 1474$ & $18.3 \% \chi^{2}=3.288, \mathrm{p}=0.070$ \\
\hline difficulties sleeping through the night & $234 / 3009$ & $7.8 \%$ & $110 / 1535$ & $7.2 \%$ & $124 / 1474$ & $8.4 \% \quad \chi^{2}=1.629, p=0.202$ \\
\hline $\begin{array}{l}\text { difficulties falling asleep and difficulties sleeping } \\
\text { through the night }\end{array}$ & 66/3009 & $2.2 \%$ & $27 / 1535$ & $1.8 \%$ & $39 / 1474$ & $2.6 \% \quad \chi^{2}=2.757, p=0.097$ \\
\hline \multicolumn{7}{|l|}{14 - 17 years (self report) } \\
\hline sleep problems in general & $948 / 4590$ & $20.7 \%$ & $393 / 2353$ & $16.7 \%$ & $555 / 2237$ & $24.8 \% \chi^{2}=46.002, p=0.000$ \\
\hline difficulties falling asleep & $693 / 4591$ & $15.1 \%$ & $300 / 2354$ & $12.7 \%$ & $393 / 2237$ & $17.6 \% \chi^{2}=20.826, \mathrm{p}=0.000$ \\
\hline difficulties sleeping through the night & $365 / 4591$ & $8.0 \%$ & $120 / 2234$ & $5.1 \%$ & $245 / 2237$ & $11.0 \% \chi^{2}=53.719, \mathrm{p}=0.000$ \\
\hline $\begin{array}{l}\text { difficulties falling asleep and difficulties sleeping } \\
\text { through the night }\end{array}$ & $146 / 4590$ & $3.2 \%$ & $39 / 2353$ & $1.7 \%$ & $107 / 2237$ & $4.8 \% \chi^{2}=36.381, p=0.000$ \\
\hline
\end{tabular}

\section{Discussion}

The present study is one of the first publications of data for sleep duration from early infancy to late adolescence of a large sample. Similar to previous studies evaluating sleep of children and adolescents, the total sleep time decreases from $14.28 \mathrm{~h}$ per night (SD 2.33) at the age of six months to $7.56(\mathrm{SD}=1.68)$ at the age of 17 (Klackenberg et al.; Bamford et al.; Jacklin et al., Gulliford et al.) [2]-[5].

It is interesting that Iglowstein et al., 2003 as well as Laberge et al. found mean values that were consistently 
Table 5. Short and long sleepers and association with sleep problems

\begin{tabular}{|c|c|c|c|c|c|}
\hline \multirow[b]{2}{*}{ age (years) } & \multirow[b]{2}{*}{ averaged sleep duration (h) } & \multicolumn{3}{|c|}{ prevalence of sleep problems } & \\
\hline & & $\begin{array}{l}\text { short sleepers } \\
\quad(<1 \text { sd) }\end{array}$ & normal sleepers & $\begin{array}{l}\text { long sleepers } \\
\quad \text { (>1 sd) }\end{array}$ & \\
\hline 0 - 2 years & $\mathrm{m}=12.90(\mathrm{sd}=1.71)$ & $\begin{array}{c}127 / 376 \\
33.8 \%\end{array}$ & $\begin{array}{c}343 / 1593 \\
22.2 \%\end{array}$ & $\begin{array}{c}30 / 306 \\
9.8 \%\end{array}$ & $\chi^{2}=55.819, p=0.000$ \\
\hline $3-6$ years & $\mathrm{m}=10.92(\mathrm{sd}=1.11)$ & $\begin{array}{l}76 / 233 \\
32.6 \%\end{array}$ & $\begin{array}{c}453 / 3077 \\
14.7 \%\end{array}$ & $\begin{array}{l}29 / 198 \\
14.6 \%\end{array}$ & $\chi^{2}=51.108, p=0.000$ \\
\hline 7 - 10 years & $\mathrm{m}=9.90(\mathrm{sd}=0.88)$ & $\begin{array}{c}261 / 983 \\
26.6 \%\end{array}$ & $\begin{array}{c}261 / 1928 \\
13.5 \%\end{array}$ & $\begin{array}{l}80 / 765 \\
10.5 \%\end{array}$ & $\chi^{2}=105.232, p=0.000$ \\
\hline 11 - 13 years & $\mathrm{m}=9.09(\mathrm{sd}=1.43)$ & $\begin{array}{c}122 / 271 \\
45.0 \%\end{array}$ & $\begin{array}{c}511 / 2431 \\
21.0 \%\end{array}$ & $\begin{array}{l}54 / 278 \\
19.4 \%\end{array}$ & $\chi^{2}=81.456, p=0.000$ \\
\hline 14 - 17 years & $\mathrm{m}=7.96(\mathrm{sd}=1.53)$ & $\begin{array}{c}227 / 662 \\
34.3 \%\end{array}$ & $\begin{array}{c}642 / 3234 \\
19.5 \%\end{array}$ & $\begin{array}{l}76 / 547 \\
12.2 \%\end{array}$ & $\chi^{2}=105.071, p=0.000$ \\
\hline
\end{tabular}

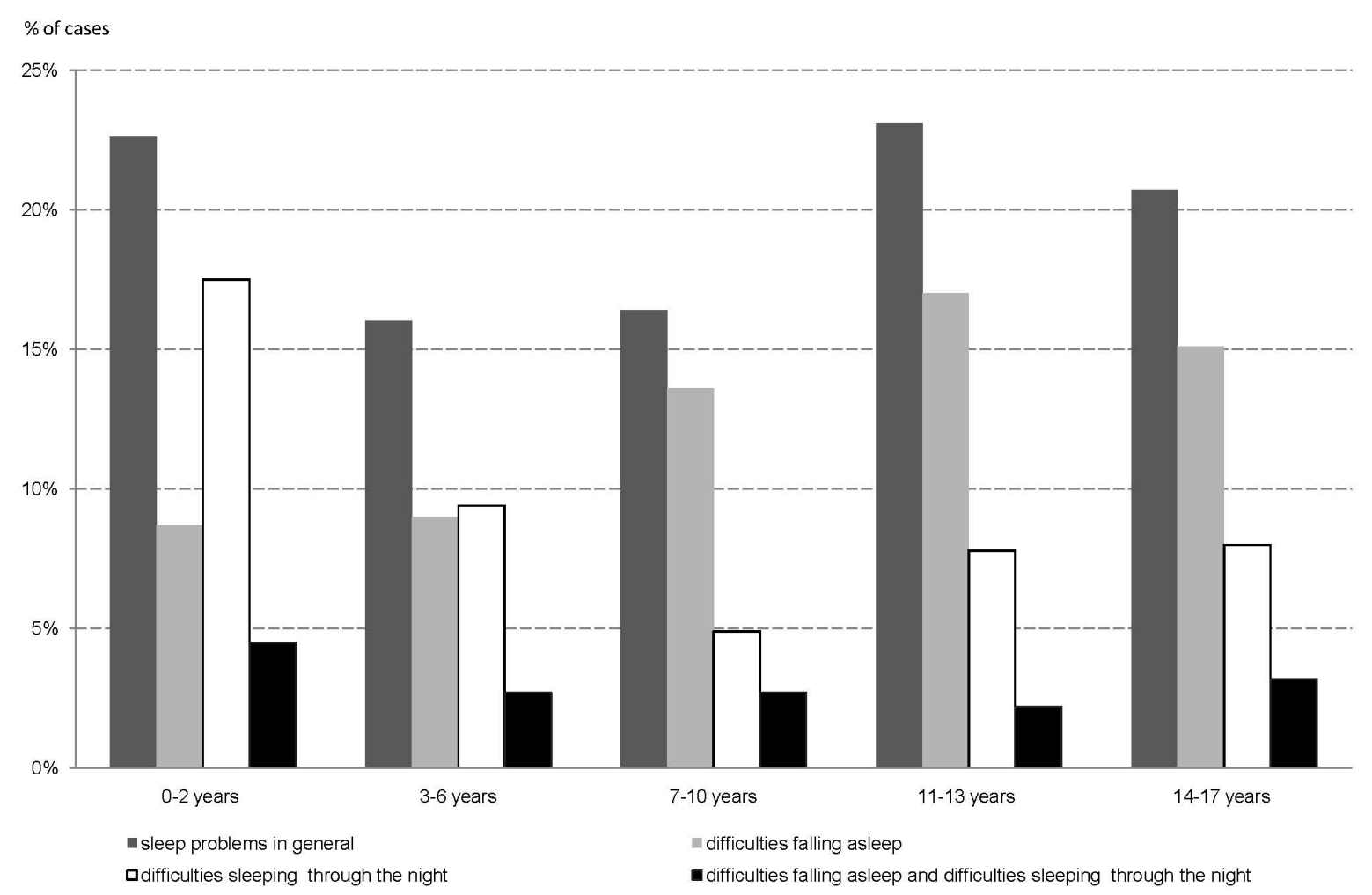

Figure 3. Prevalence of sleep problems in general, difficulties falling asleep, difficulties sleeping through the night and the combination of difficulties falling asleep and difficulties sleeping through night compared between the age groups.

higher compared with what we found. On the other hand, the results are in line with the general tendency of lower sleeping times [13].

One of the objectives of this study was to evaluate gender differences or variations between children and adolescents, the results of these comparisons are illustrated above. Before puberty no gender differences were found. However, with onset of puberty gender differences were clearly seen between boys and girls. With the age of 13 years girls show more sleep problems in general than boys. This age specific development is becoming significantly stronger at the age of 14 to 17 years. In this age group girls show significantly more sleep problems, difficulties falling asleep, difficulties sleeping through the night and both symptoms than boys. These results are in line with Krishnan and Collop who showed that gender differences in sleep become apparent after onset of puberty because of hormonal changes [29].

As several studies showed, many children and adolescents do not obtain adequate nocturnal sleep. In the full 
sample $19.5 \%$ of the children and adolescents showed unspecified sleep problems. This result is in difference to other studies who reported who reported sleep problems in $21.2 \%$ to $25 \%$. But—as mentioned-it has to bear in mind that prevalence rate of insomnia changes due to diagnostic criteria in age groups and countries [27]. Struggling with falling asleep was described in $13 \%$ which is also a smaller percentage than what was reported of other European studies [12] and difficulties sleeping through the night were showed by $8.8 \%$ of the children and adolescents which is also a smaller proportion than in the Spanish study [12]. An amount of 3\% reported both symptoms. These are in line with other studies which showed that many children have sleep problems during childhood [15]-[18] [30].

Looking at the age specific development of sleep problems it can be assumed that difficulties of falling asleep become a more frequent problem rising with age whereas problems sleeping through the night are less common within older children.

In our study the short sleepers had in $32.6 \%$ to $45.0 \%$ sleep problems whereas of normal sleepers $13.7 \%$ to $22.3 \%$ showed sleep problems. These results correspond with previous studies that showed that short sleep is significantly associated with more sleep problems as sleep deprivation [36].

It has to be taken into account that in this study, the length of the child's sleep was assessed by the parents or the child him- or herself within a questionnaire. Therefore these data are subjective. To install more objective measures as actigraphs would have been helpful.

In sum, this study may help clinicians to evaluate sleep problems in childhood and adolescence bearing in mind that young children more often suffer from problems sleeping through the night, whereas older children and adolescents often suffer from problems falling asleep. As sleep duration and sleep problems are associated with various problems as concentration or behavior problems, an adequate and early treatment is necessary to prevent further impairments.

\section{Acknowledgements}

We acknowledge support for the Article Processing Charge by the Deutsche Forschungsgemeinschaft and the Open Access Publication Fund of Bielefeld University.

\section{References}

[1] Laberge, L., Petit, D., Simard, C., Vitaro, F., Tremblay, R.E. and Montplaisir, J. (2001) Development of Sleep Patterns in Early Adolescence. Journal of Sleep Research, 10, 59-67. http://dx.doi.org/10.1046/j.1365-2869.2001.00242.x

[2] Gulliford, M.C., Price, C.E., Rona, R.J. and Chinn, S. (1990) Sleep Habits and Height at Ages 5 to 11. Archives of Disease in Childhood, 65, 119-122. http://dx.doi.org/10.1136/adc.65.1.119

[3] Jacklin, C.N., Snow, M.E., Gahart, M. and Maccoby, E.E. (1980) Sleep Pattern Development from 6 through 33 Months. Journal of Pediatric Psychology, 5, 295-303. http://dx.doi.org/10.1093/jpepsy/5.3.295

[4] Bamford, F.N., Bannister, R.P., Benjamin, C.M., Hillier, V.F., Ward, B.S. and Moore, W.M. (1990) Sleep in the First Year of Life. Developmental Medicine and Child Neurology, 32, 718-724. http://dx.doi.org/10.1111/j.1469-8749.1990.tb08432.x

[5] Klackenberg, G. (1968) The Development of Children in a Swedish Urban Community. A Prospective Longitudinal Study. Acta Paediatrica, 57, 105-121. http://dx.doi.org/10.1111/j.1651-2227.1968.tb06044.X

[6] Seo, W.S., Sung, H.-M., Lee, J.H., Koo, B.H., Kim, M.J., Kim, S.Y., Choi, S.-J. and Im Shin, H. (2010) Sleep Patterns and Their Age-Related Changes in Elementary-School Children. Sleep Medicine, 11, 569-575. http://dx.doi.org/10.1016/j.sleep.2010.03.011

[7] Liu, X., Liu, L., Owens, J.A. and Kaplan, D.L. (2005) Sleep Patterns and Sleep Problems among Schoolchildren in the United States and China. Pediatrics, 115, 241-249. http://dx.doi.org/10.1542/peds.2004-0815f

[8] Liu, X., Ma, Y., Wang, Y., Jiang, Q., Rao, X., Lu, X. and Teng, H. (2005) Brief Report: An Epidemiologic Survey of the Prevalence of Sleep Disorders among Children 2 to 12 Years Old in Beijing, China. Pediatrics, 115, 266-268. http://dx.doi.org/10.1542/peds.2004-0815i

[9] Iglowstein, I., Jenni, O.G., Molinari, L. and Largo, R.H. (2003) Sleep Duration from Infancy to Adolescence: Reference Values and Generational Trends. Pediatrics, 111, 302-307. http://dx.doi.org/10.1542/peds.111.2.302

[10] Thorleifsdottir, B., Björnsson, J.K., Benediktsdottir, B., Gislason, T. and Kristbjarnarson, H. (2002) Sleep and Sleep Habits from Childhood to Young Adulthood over a 10-Year Period. Journal of Psychosomatic Research, 53, 529-537. http://dx.doi.org/10.1016/S0022-3999(02)00444-0 
[11] Nixon, G.M., Thompson, J.M.D., Han, D.Y., Becroft, D.M., Clark, P.M., Robinson, E., Waldie, K.E., Wild, C.J., Black, P.N. and Mitchell, E.A. (2008) Short Sleep Duration in Middle Childhood: Risk Factors and Consequences. Sleep, 31, 71-78.

[12] García-Jiménez, M.A., Salcedo-Aguilar, F., Rodríguez-Almonacid, F.M., Redondo-Martínez, M.P., Monterde-Aznar, M.L., Marcos-Navarro, A.I. and Torrijos-Martínez, M.P. (2004) Prevalencia de los trastornos del sueño en adolescentes de Cuenca, España. Revista de Neurologia, 39, 18-24.

[13] Dollman, J., Ridley, K., Olds, T. and Lowe, E. (2007) Trends in the Duration of School-Day Sleep among 10- to 15Year-Old South Australians between 1985 and 2004. Acta Paediatrica, 96, 1011-1014. http://dx.doi.org/10.1111/j.1651-2227.2007.00278.x

[14] Tynjälä, J., Kannas, L. and Välimaa, R. (1993) How Young Europeans Sleep. Health Education Research, 8, 69-80. http://dx.doi.org/10.1093/her/8.1.69

[15] Roberts, R.E., Roberts, C.R. and Chen, I.G. (2002) Impact of Insomnia on Future Functioning of Adolescents. Journal of Psychosomatic Research, 53, 561-569. http://dx.doi.org/10.1016/S0022-3999(02)00446-4

[16] Roberts, R.E., Roberts, C.R. and Chan, W. (2006) Ethnic Differences in Symptoms of Insomnia among Adolescents. Sleep, 29, 359-365.

[17] Ohayon, M.M., Roberts, R.E., Zulley, J., Smirne, S. and Priest, R.G. (2000) Prevalence and Patterns of Problematic Sleep among Older Adolescents. Journal of the American Academy of Child and Adolescent Psychiatry, 39, 1549-1556. http://dx.doi.org/10.1097/00004583-200012000-00019

[18] Liu, X., Uchiyama, M., Okawa, M. and Kurita, H. (2000) Prevalence and Correlates of Self-Reported Sleep Problems among Chinese Adolescents. Sleep, 23, 27-34.

[19] Johnson, E.O., Roth, T., Schultz, L. and Breslau, N. (2006) Epidemiology of DSM-IV Insomnia in Adolescence: Lifetime Prevalence, Chronicity, and an Emergent Gender Difference. Pediatrics, 117, e247-e256. http://dx.doi.org/10.1542/peds.2004-2629

[20] Li, S., Zhu, S., Jin, X., Yan, C., Wu, S., Jiang, F. and Shen, X. (2010) Risk Factors Associated with Short Sleep Duration among Chinese School-Aged Children. Sleep Medicine, 11, 907-916. http://dx.doi.org/10.1016/j.sleep.2010.03.018

[21] Shi, Z., Taylor, A.W., Gill, T.K., Tuckerman, J., Adams, R. and Martin, J. (2010) Short Sleep Duration and Obesity among Australian Children. BMC Public Health, 10, 609. http://dx.doi.org/10.1186/1471-2458-10-609

[22] Padez, C., Mourao, I., Moreira, P. and Rosado, V. (2009) Long Sleep Duration and Childhood Overweight/Obesity and Body Fat. American Journal of Human Biology: The Official Journal of the Human Biology Council, 21, 371-376. http://dx.doi.org/10.1002/ajhb.20884

[23] Wolfson, A.R. and Carskadon, M.A. (1998) Sleep Schedules and Daytime Functioning in Adolescents. Child Development, 69, 875-887. http://dx.doi.org/10.1111/j.1467-8624.1998.tb06149.x

[24] Loessl, B., Valerius, G., Kopasz, M., Hornyak, M., Riemann, D. and Voderholzer, U. (2008) Are Adolescents Chronically Sleep-Deprived? An Investigation of Sleep Habits of Adolescents in the Southwest of Germany. Child: Care, Health and Development, 34, 549-556. http://dx.doi.org/10.1111/j.1365-2214.2008.00845.X

[25] Patel, S.R., Malhotra, A., Gottlieb, D.J., White, D.P. and Hu, F.B. (2006) Correlates of Long Sleep Duration. Sleep, 29, 881-889.

[26] Owens, J. (2008) Classification and Epidemiology of Childhood Sleep Disorders. Primary Care, 35, 533-546. http://dx.doi.org/10.1016/j.pop.2008.06.003

[27] Ferber, R. (1996) Clinical Assessment of Child and Adolescent Sleep Disorders. Child and Adolescent Psychiatric Clinics of North America, 5, 569-579.

[28] Lehmkuhl, G., Fricke-Oerkermann, L., Wiater, A. and Mitschke, A. (2008) Sleep Disorders in Children Beginning School: Their Causes and Effects. Deutsches Ärzteblatt International, 105, 809-814.

[29] Krishnan, V. and Collop, N.A. (2006) Gender Differences in Sleep Disorders. Current Opinion in Pulmonary Medicine, 12, 383-389. http://dx.doi.org/10.1097/01.mcp.0000245705.69440.6a

[30] Johnson, E.O., Roth, T., Schultz, L. and Breslau, N. (2006) Epidemiology of DSM-IV Insomnia in Adolescence: Lifetime Prevalence, Chronicity, and an Emergent Gender Difference. Pediatrics, 117, e247-e256. http://dx.doi.org/10.1542/peds.2004-2629

[31] Kurth, B.-M. (2007) Der Kinder- und Jugendgesundheitssurvey (KiGGS): Ein Uberblick über Planung, Durchführung und Ergebnisse unter Berücksichtigung von Aspekten eines Qualitätsmanagements. Bundesgesundheitsblatt, Gesundheitsforschung, Gesundheitsschutz, 50, 533-546. http://dx.doi.org/10.1007/s00103-007-0214-x

[32] Kamtsiuris, P., Lange, M. and Schaffrath Rosario, A. (2007) Der Kinder- und Jugendgesundheitssurvey (KiGGS): Stichprobendesign, Response und Nonresponse-Analyse. Bundesgesundheitsblatt, Gesundheitsforschung, Gesundheitsschutz, 50, 547-556. http://dx.doi.org/10.1007/s00103-007-0215-9 


\section{A. A. Schlarb et al.}

[33] Hölling, H., Kamtsiuris, P., Lange, M., Thierfelder, W., Thamm, M. and Schlack, R. (2007) Der Kinder- und Jugendgesundheitssurvey (KiGGS): Studienmanagement und Durchführung der Feldarbeit. Bundesgesundheitsblatt, Gesundheitsforschung, Gesundheitsschutz, 50, 557-566. http://dx.doi.org/10.1007/s00103-007-0216-8

[34] Kurth, B.M., Bergmann, K.E., Hölling, H., Kahl, H., Kamtsiuris, P. and Thefeld, W. (2002) Der bundesweite Kinderund Jugendgesundheitssurvey. Das Gesundheitswesen, 64, S3-S11. http://dx.doi.org/10.1055/s-2002-39003

[35] American Academy of Sleep Medicine (2005) International Classification of Sleep Disorders. 2nd Edition, Diagnostic and Coding Manual, American Academy of Sleep Medicine, Westchester.

[36] Carskadon, M.A., Acebo, C. and Jenni, O.G. (2004) Regulation of Adolescent Sleep: Implications for Behavior. Annals of the New York Academy of Sciences, 1021, 276-291. http://dx.doi.org/10.1196/annals.1308.032 